\title{
Luminescent Properties of Nanocomposites on the Basis of Isotactic Polypropylene and Zirconium Dioxide Nanoparticles
}

Hajiyeva FV, Ramazanov MA* and Maharramov AM

Baku State University, Department Chemical Physics of Nanomaterials, Nanoresearch Laboratory, ZahidKhalilov Str. 23, Baku, Azerbaijan

\begin{abstract}
At the paper studied luminescent properties of nanocomposites on the basis isotactic polypropylene and zirconium dioxide nanoparticles. Shown that change of nanocomposite colour and maximum amplitude of UV spectres depend on $\mathrm{ZrO}_{2}$ nanoparticles sizes in polypropylene. Found that mean-square roughness of PP $+1 \% \mathrm{ZrO}_{2}$ composition surface in dependence of cooling rate $\beta$ changes, i.e. for the samples at regime $\beta_{1}=20 \mathrm{deg} / \mathrm{min}$ the roughness is $40-60 \mathrm{~nm}$, whereas for the samples prepared at $\beta_{2}=2 \mathrm{deg} / \mathrm{min}$ the roughness is $150-220 \mathrm{~nm}$. Shown that polypropylene matrix works as chemically stable preservative of nanoparticles, preserving its spectral peculiarities. Sufficiently strong interphases interactions between PP matrix and $\mathrm{ZrO}_{2}$ nanoparticles change its luminescent properties.
\end{abstract}

Keywords: Nanocomposite; Polypropylene; Zirconium dioxide; Photoluminescence

\section{Introduction}

Polymeric nanocomposite materials, composed of two or more phases, require the development of physical and chemical basis of preparation of new active elements by means of modification of its structure and properties. These materials combine the positive properties of individual components of composite and acquire photo luminescent properties with high physic-mechanic characteristics [13]. Nanocomposites have got the unique properties, caused not only by too little sizes of metallic and semiconductor nanoparticles, but also by peculiarities of polymeric matrix structure. The polymeric matrixes allow organization of nanoparticles into supramolecular structures, which considerably increase the extraordinary properties of nanoparticles [4-5].

In the present work have been studied luminescent properties of nanocomposites on the basis of isotactic polypropylene and zirconium dioxide nanoparticles.

\section{Experimental Part}

As a polymeric matrix the powder of isotactic polypropylene with grain size $0.5-1.0 \mathrm{mcm}$, was used. The filler were nanoparticles of zirconium dioxide $\mathrm{ZrO}_{2}$ with size $21 \mathrm{~nm}$, stabilized by $3 \%$ of yttrium oxide $\left(\mathrm{Y}_{2} \mathrm{O}_{3}\right)$.

Synthesis of nanocomposites of $\mathrm{PP}+\mathrm{ZrO}_{2}$ was carried out by introduction of $\mathrm{ZrO}_{2}$ nanoparticles into the polymeric solution. Initial powder of isotactic with grain size $0.5-1.0 \mu \mathrm{m}$ was solved in toluene at $120^{\circ} \mathrm{C}$. The crystallization of polymer around zirconium dioxide nanoparticles and formation of large agglomerates without uniform distribution of nanoparticles in polymer solution was observed at immediate addition of nanopowders. This is explained that nanoparticles perform the centres of germ formation [6]. For uniform distribution of nanoparticles in polymer solution the nanopowders of zirconium dioxide was preliminary wet in toluene at light heating. Then the mixture was added to polymer solution and intensively stirred in 1 hour. The formed blend of polymer and zirconium dioxide nanoparticles was poured in Petri dish and dried at ambient in 24 hours in the air. The samples of nanocomposites $\mathrm{PP}+\mathrm{ZrO}$, with various volume content of $\mathrm{ZrO}_{2}$ were prepared by hot pressing method at melting point of $\mathrm{PP}$ and pressure $10 \mathrm{MPa}$ with further cooling till room temperature with rate $\beta_{1}=20 \mathrm{deg} / \mathrm{min}$ and $\beta_{1}=2 \mathrm{deg} / \mathrm{min}$. The analyses of microstructure of samples were performed on optical microscope Motic AE 30/31. The morphology of nanocomposites, including distribution of zirconium dioxide nanoparticles in polymeric matrix was studied by scanning probe microscopy (AFM INTEGRA PRIMA).

The luminescent properties of nanocomposite films were performed on spectrofluorimeter Varian Cary Eclipse. The absorption spectra were performed on spectrophotometer SF Perkin-Elmer at 200$700 \mathrm{~nm}$. All measurements were carried out at ambient temperature.

\section{Result and Discussion}

UV spectroscopy analysis of nanocomposite $\mathrm{PP}+\mathrm{ZrO}_{2}$ was carried out for study of $\mathrm{ZrO}_{2}$ formation in polypropylene. Absorption spectra were performed on spectrophotometer Perkin Elmer, USA The measurements were taken at ambient. The Figure 1 presents the absorption spectra of pristine polypropylene and nanocomposites

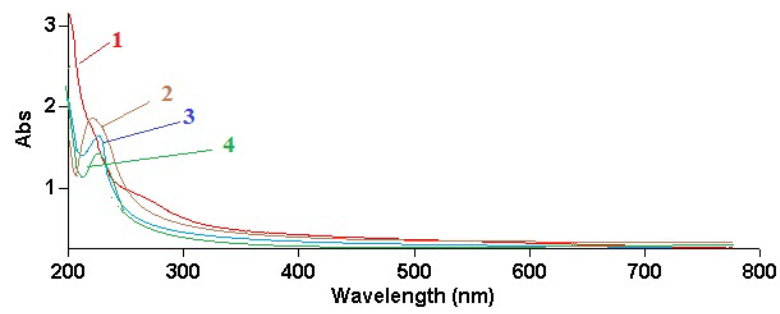

Figure 1: UV spectra of nanocomposite $\mathrm{PP}+\mathrm{ZrO}_{2}$ 1. $\mathrm{PP}, 2 . \mathrm{PP}+1 \% \mathrm{ZrO}_{2}, 3$. $\mathrm{PP}+3 \% \mathrm{ZrO}_{2}, 4 . \mathrm{PP}+5 \% \mathrm{ZrO}_{2}$.

*Corresponding author: Ramazanov MA, Baku State University, Department Chemical Physics of Nanomaterials, Nanoresearch Laboratory, ZahidKhalilov Str. 23, Baku, Azerbaijan, Tel: +994-12-5387295; Fax: +994-12-598-33-76; E-mail: mamed_r50@mail.ru

Received October 28, 2015; Accepted December 12, 2015; Published December 22, 2015

Citation: Hajiyeva FV, Ramazanov MA, Maharramov AM (2015) Luminescent Properties of Nanocomposites on the Basis of Isotactic Polypropylene and Zirconium Dioxide Nanoparticles. J Nanomedic Nanotechnol S7:003. doi:10.4172/2157-7439.S7-003

Copyright: (c) 2015 Hajiyeva FV, et al. This is an open-access article distributed under the terms of the Creative Commons Attribution License, which permits unrestricted use, distribution, and reproduction in any medium, provided the original author and source are credited. 
Citation: Hajiyeva FV, Ramazanov MA, Maharramov AM (2015) Luminescent Properties of Nanocomposites on the Basis of Isotactic Polypropylene and Zirconium Dioxide Nanoparticles. J Nanomedic Nanotechnol S7:003. doi:10.4172/2157-7439.S7-003

$\mathrm{PP}+\mathrm{ZrO}_{2}$ with different $\mathrm{ZrO}_{2}$ volume content.

As it shown in Figure 1 the intensity of observed absorption at $235 \mathrm{~nm}$ change with various concentration of $\mathrm{ZrO}_{2}$ in nanocomposite was found that increasing of nanoparticles concentration led to colour change of nanocomposite. The change of nanocomposite colour and $\mathrm{UV}$ spectra intensity is connected with increasing of $\mathrm{ZrO}_{2}$ nanoparticles sizes in polypropylene.

The optic microscopy method performed the study of the surface of nanocomposite $\mathrm{PP}+\mathrm{ZrO}_{2}$, at various concentration of $\mathrm{ZrO}_{2}$ and different temperature-time regime of crystallization of nanocomposite melt.
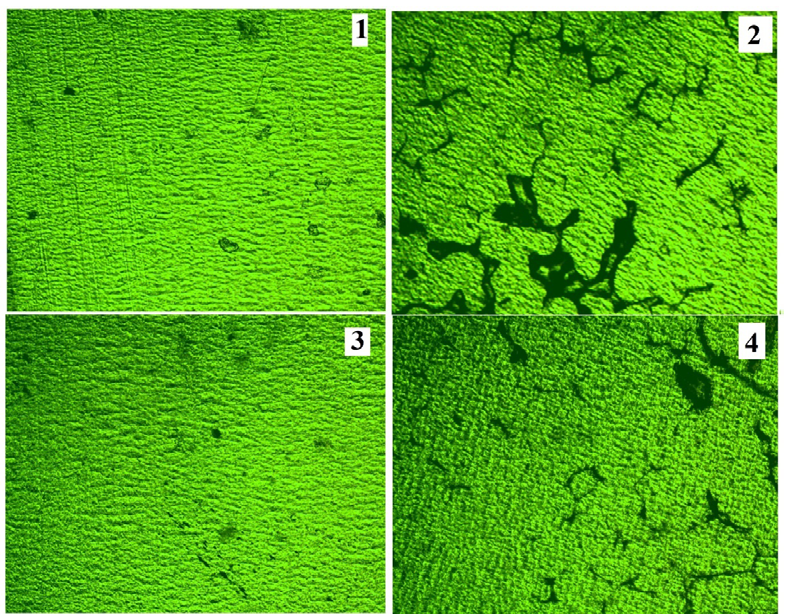

Figure 2: Microstructure of nanocomposite on the basis of polypropylene and zirconium dioxide prepared at regimes $\beta_{1}=20 \mathrm{deg} / \mathrm{min}(1,3)$ and $\beta_{2}=2$ $\operatorname{deg} / \min (2,4) .1 . \mathrm{PP}+1 \% \mathrm{ZrO}_{2}, 3 . \mathrm{PP}+3 \% \mathrm{ZrO}_{2}, 2 . \mathrm{PP}+1 \% \mathrm{ZrO}_{2}, 4 . \mathrm{PP}+3 \%$ $\mathrm{ZrO}_{2}$
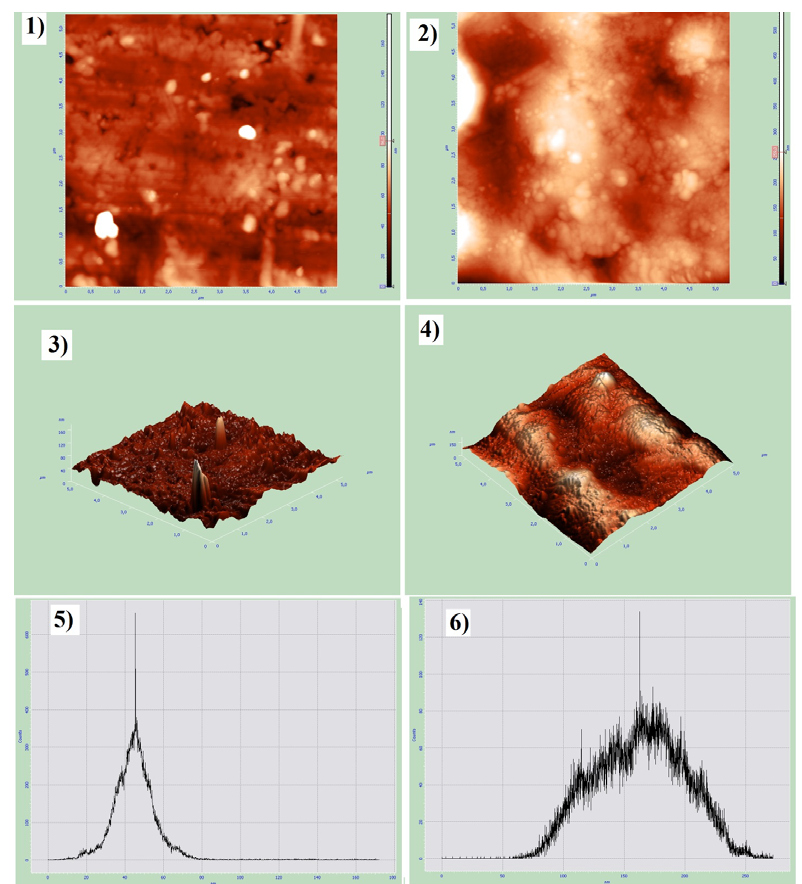

4)

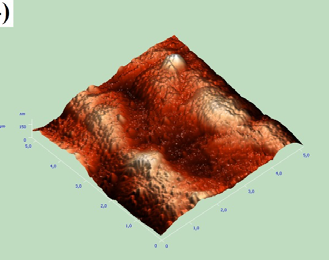

6)

Figure 3: $\mathrm{AFM}$ images of $\mathrm{PP}+1 \% \mathrm{ZrO}$ nanocomposite prepared at regimes with cooling rate $\beta_{1}=20 \mathrm{deg} / \mathrm{min}(1,3,5)$ and $\beta_{2}=2 \mathrm{deg} / \mathrm{min}(2,4,6)$.
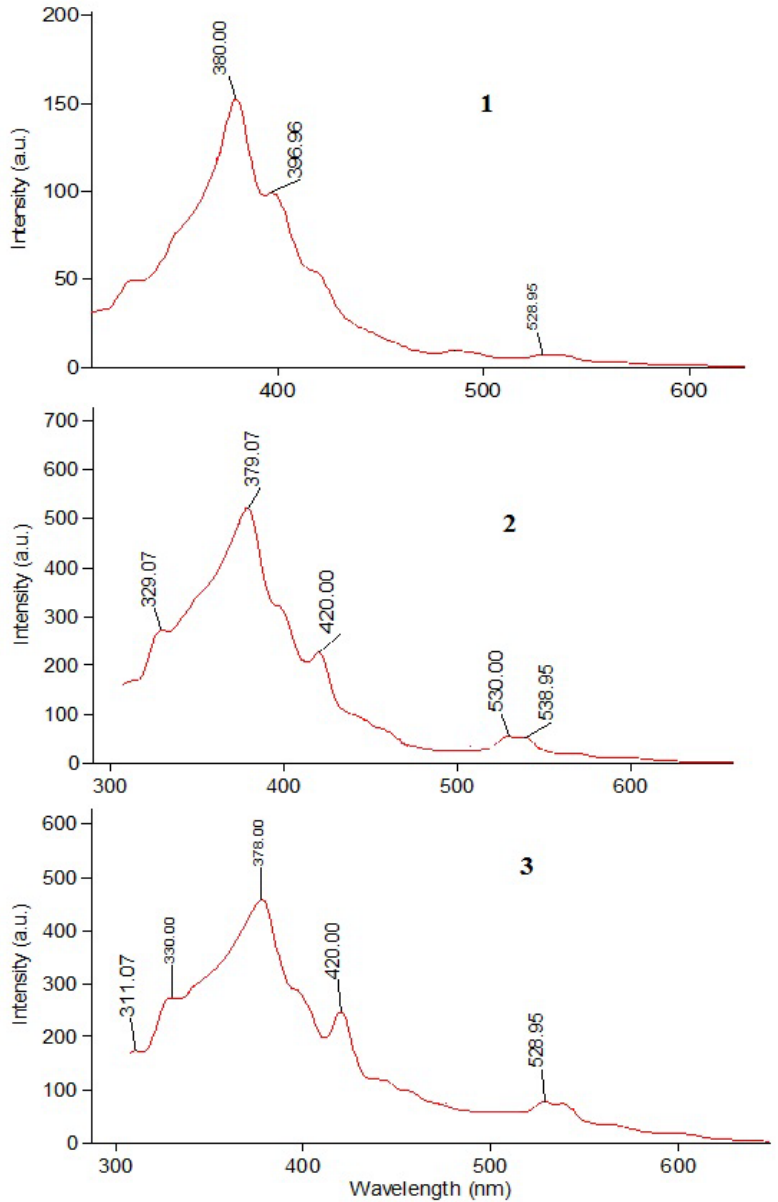

Figure 4: Luminescent spectra of nanocomposite $\mathrm{PP}+\mathrm{ZrO}{ }_{2}, \mathrm{Em} \_\mathrm{ex} 270 \_$1) $\left.\left.\mathrm{PP}+1 \% \mathrm{ZrO}_{2}, 2\right) \mathrm{PP}+3 \% \mathrm{ZrO}_{2}, 3\right) \mathrm{PP}+5 \% \mathrm{ZrO}$

At Figure 2 shown the microstructure of nanocomposites $\mathrm{PP}+\mathrm{ZrO}_{2}$ prepared at various concentration of $\mathrm{ZrO}_{2}$ and different temperaturetime regimes $\beta_{1}=20 \mathrm{deg} / \mathrm{min}$ and $\beta_{2}=2 \mathrm{deg} / \mathrm{min}$. Optic microscopy study of nanocomposite reveal the dependence of morphology and structure elements of nanocomposite on various concentration of $\mathrm{ZrO}$ and different temperature-time regime of crystallization.

At Figure 3 shown AFM images of $\mathrm{PP}+1 \% \mathrm{ZrO}_{2}$ nanocomposite prepared at regimes with cooling rate $20 \mathrm{deg} / \mathrm{min}$ and $2 \mathrm{deg} / \mathrm{min}$. AFM study of contour of nanocomposite samples $\mathrm{PP}+1 \% \mathrm{ZrO}_{2}$, prepared at various different temperature-time regime of crystallization revealed changes of structural elements on the surface of composites samples $\mathrm{PP}+1 \% \mathrm{ZrO}_{2} .2 \mathrm{D}$ and $3 \mathrm{D}$ image of nanocomposite prepared at different temperature-time regime of crystallization demonstrate the change of contour of samples, i.e. the sizes of structural elements with increasing of cooling rate reduce. At picture 3 shown the analysis of surface and histogram of elements values of nanocomposite $\mathrm{PP}+1 \% \mathrm{ZrO}_{2}$ images, prepared at different temperature-time regime of crystallization.

Shown that mean-square roughness of $\mathrm{PP}+1 \% \mathrm{ZrO}_{2}$ composition surface in dependence of $\beta$ changes, i.e. for the samples at regime $\beta_{1}$ $=20 \mathrm{deg} / \mathrm{min}$ the roughness is $40-60 \mathrm{~nm}$, whereas for the samples prepared at $\beta_{2}=2 \mathrm{deg} / \mathrm{min}$ the roughness is $150-220 \mathrm{~nm}$.

Have been studied photoluminescent spectra of $\mathrm{PP}+\mathrm{ZrO}_{2}$ nanocomposite prepared at various concentrations of $\mathrm{ZrO}_{2}$ 
Citation: Hajiyeva FV, Ramazanov MA, Maharramov AM (2015) Luminescent Properties of Nanocomposites on the Basis of Isotactic Polypropylene and Zirconium Dioxide Nanoparticles. J Nanomedic Nanotechnol S7:003. doi:10.4172/2157-7439.S7-003

Page 3 of 3

nanoparticles. At picture 4 presented photoluminescent spectra of nanocomposite 1) $\left.\left.\mathrm{PP}+1 \% \mathrm{ZrO}_{2}, 2\right) \mathrm{PP}+3 \% \mathrm{ZrO}_{2}, 3\right) \mathrm{PP}+5 \% \mathrm{ZrO}_{2}$. The maximums of luminescence observed at $330 \mathrm{~nm}, 380 \mathrm{~nm}, 400 \mathrm{~nm}, 420$ $\mathrm{nm}$ and $538 \mathrm{~nm}$.

Exiting of luminescence for given wavelength is connected with optical passages between valence zone and conductive zone shown that increasing of zirconium dioxide concentration led to increasing of intensity at $330 \mathrm{~nm}, 420 \mathrm{~nm}, 530 \mathrm{~nm}, 538 \mathrm{~nm}$. The intensity of luminescence depending of concentration changes with extremum, i.e. the maximum luminescence is observed at $3 \%$ volume concentration. The analysis of prepared nanocomposites revealed that increasing of $\mathrm{ZrO}_{2}$ nanoparticles concentration in PP and rise of its specific surface led to increasing of interphases interactions between components of nanocompositions. Increasing of interphases interactions led to binding of nanoparticles to polymer macromolecules and as sequence increasing of luminescence intensity (Figure 4).

\section{Conclusion}

These results also demonstrate that intermolecular interactions in photoluminescent active environment considerably influence on its spectral characteristics. From these experimental results can be concluded that polypropylene matrix works as chemically stable preservative of nanoparticles, preserving its spectral peculiarities, as well as there are sufficiently strong interphases interactions between PP matrix and $\mathrm{ZrO}_{2}$ nanoparticles that change its luminescent properties.

\section{References}

1. Badamshina ER, Gafurova MP (2008) Modifying the properties of polymers by doping $\mathrm{C}_{60}$ fullerene. Journal Macromolecular compounds Ser A 50: 15721584.

2. Vossmeyer T, Katsikas L, Giersig M, Popovic I (1994) J Chem Phys 98: 76657673.

3. Maharramov A, Ramazanov M, Saboktakin MR (2013) Advanced Nanocomposites Types, Properties, and Applications. Nova Publisher 334.

4. Maharramov AM, Ramazanov MA, Hajiyeva FV (2014) Structure and dielectric properties of Nanocomposites on the basis of high-density polyethylene and lead sulphide. J Chalcogenide Letters 11: 175-180.

5. Maharramov AM, Ramazanov MA, Alizade RA, Asilbeyli PB (2013) Structure and dielectric properties of nanocomposites on the bas of polyethylene with $\mathrm{Fe}_{3} \mathrm{O}_{4}$ nanopatricles Digest. Journal of Nanomaterials and Biostructures 8: 1447-1454

6. Magerramov AM, Ramazanov MA, Hajiyeva FV, Guliyeva VM (2013) Investigation of structure and electrophysical properties of nanocomposite materials on the basis of zirconium dioxiden in isotactic polypropylene matrix. Journal of Ovonic Research 9: 133-141 